\title{
Reply to comment on the article "The characteristics of sexual behaviour and extent of condom usage among sexually active Croatians from Eastern Croatia" carried out by Miskulin et al. and published in the J Turkish - German Gynecol Assoc 2009; 10: 142-7
}

J Turkish-German Gynecol Assoc 2009; 10: 142-7 de yayınlanmus olan “The characteristics of sexual behaviour and extent of condom usage among sexually active Croatians from Eastern Croatia" adlı makalenin yorumuna yanıt

Maja Miskulin

Department of Public Health, University of J osip J uraj Strossmayer, Osijek, Croatia (Hrvatska)

Dear Sir,

This is a reply to the Letter to the Editor published in The Journal of the Turkish German Gynecological Association, 2010(2):118. As authors we are very pleased that our work has received the interest of your readers and distinguished colleagues. As they have very well noticed we did not include the answers to question 12. "I have NEVER in my lifetime involved myself in sexual activities combined with drug or alcohol abuse without condom: a) yes b) no" in the text of our article. The reason for this is that the main goal of our research was to determine the extent of condom usage as a method of protection from sexually transmitted infections (STIs) in the studied population (sexually active Croatians from Eastern Croatia, mean age 31.31 $\$ 8.42$ years) during each and every possible situation, not only in situations such as risky circumstances connected with drug or alcohol abuse that were found to be related to inconsistent or non-use of condoms and increased difficulty to implement condom use (1). In an attempt to show our data in the most concise and clear way, we simply left out some findings from the result section and aimed to discuss these separately.

Considering the data regarding the hepatitis $B$ virus vaccination we are very well aware that hepatitis $B$ is classified as a sexually transmitted infection (2). That was the reason why we included this question in our questionnaire in the first place. However,after we analysed our data we saw that, as we expected, only $22 / 278$ (7.9\%) study subjects had received hepatitis $B$ vaccination, $11 / 22$ (50\%) of them from the young- est 18-24 age group. Of 62 subjects reporting sexual relations with two or more partners during the one-year period, five ( $8.1 \%)$ had received hepatitis $B$ vaccination. Bearing in mind the allowed length of the manuscript and our attempt to make our investigation and our results as clear as possible, we omitted these results from the text. Due to the interest of that aspect of our work shown by your readers this is maybe the appropriate place to comment on results regarding the hepatitis B vaccination and the reasons for our lack of surprise at such a low prevalence of vaccinated persons in our sample. Actually, the hepatitis B vaccination was not mandatory for the entire population in Croatia until 1999 when this vaccination became part of the Croatian Vaccination Programme, and all children in the sixth grade of elementary school have been vaccinated. Since 2007, vaccination against hepatitis $B$ became mandatory vaccination for all new -borns in our country also $(3,4)$. Taking all these into account ,it is clear that in future we will have more vaccinated persons in the general population and we will be able to investigate the sexual behaviour and preferences of hepatitis $B$ immune or non immune people more accurately.

It is true that we did not define what should be considered risky sexual behaviour in our manuscript because we addressed educated readers and we thought that considering the allowed length of the manuscript it was not necessary to give this definition (which we certainly had in mind when writing the article) within the text of the manuscript. We are however very grateful to our distinguished colleagues who made such an effort and emphasized the main determinants

Address for Correspondence / Yazışma A dresi: Yard. Doç. Dr. Maja Miskulin, J. Huttlera, 431000 Osijek, Croatia (Hrvatska)

Phone: + 38531301287 e.mail: maja.miskulin@inethr

doi:10.5152/jtgga.2010.30 
of risky sexual behaviour (5) in order to make our article clearer and easily understood by the wide audience of your journal

Finally, we wish to express our sincere gratitude to the distinguished colleagues who have shown an interest in our study, considering our data to be valuable for them and all of your readers.

We look forward to further successful collaboration with your Editorial Office and active interaction with your readers.

Sincerely yours,

\section{Conflict of interest}

No conflict of interest is declared by authors.

\section{R eferences}

1. Woolf-King SE, Maisto SA. Alcohol Use and High-Risk Sexual Behavior in Sub-Saharan Africa: A Narrative Review. Arch Sex Behav DOI 10.1007/s10508-009-9516-4. Published on line in 25 August 2009.

2. Hay P, Ugwumadu A. Detecting and treating common sexually transmitted diseases. Best Pract Res Clin Obstet Gynaecol 2009; 23: 647-60.

3. Harjacek M. Vaccination and vaccines against hepatitis $B$ virus. [in Croatian] Medix 2007; 68-9.

4. Lesnikar V. Epidemiology of hepatitis B and C in Croatia. [in Croatian] Acta Med Croat 2005; 59: 377-81.

5. High risk sexual behavior. Available at: http://www.revolutionhealth. com/articles/high-risk-sexual-behavior/tw9064. Certified by Health on the Net association. (HONConduct274933). 